Им был изучен характер заражённости мух возбудителями кишечных болезней, сроки сохранения возбудителей на мухах, а также степень заражённости мух на разных по санитарному благоустройству территориях страны. Ряд его работ посвящён вопросам дезинфекции, дезинсекции и дератизации. В этой области им внесено ряд изобретений и рационализаторских предложений, которые были воплощены в профессиональную деятельность. Все работы профессора Б.Л.Шура-Бура отличались новизной постановки вопроса, применением новых методов исследований и имели большое теоретическое и практическое значение. Будучи военным медиком, полковник медицинской службы в отставке Б.Л. Шура-Бура уделял большое внимание разработке вопросов противоэпидемической защиты войск, дезинфекции в войсках и в системе гражданской обороны. Он являлся одним из авторов учебника по военной эпидемиологии и участвовал в создании Большой медицинской энциклопедии.

Большое внимание Б.Л. Шура-Бура уделял подготовке научных кадров. Под его руководством выполнены и защищены 9 кандидатских и 1 докторская диссертации.

Научно-педагогическую работу Борис Лукич успешно сочетал с общественной деятельностью, являясь бессменным председателем Рязанского отделения Всесоюзного научного общества микробиологов, эпидемиологов, паразитологов. Bce, кому посчастливилось учиться и работать с Борисом Лукичом отмечают его исключительно доброе отношение к коллегам и студентам. Он был принципиальным, требовательным руководителем, отзывчивым товарищем, широко эрудированным человеком, щедро передававшим свои знания и опыт молодёжи.

Б.Л. Шура-Бура был женат и имел дочь Галину, 1938 г. рождения.

За свой ратный труд Борис Лукич награждён орденом Красной Звезды (1951), Красного Знамени (1956), медалями «За боевые заслуги» (1946), «Ветеран Вооружённых Сил СССР», «40 лет Вооружённых Сил СССР», «50 лет Вооружённых Сил СССР», «20 лет победы в Великой Отечественной войне 1941-1945 гг.».

Умер Б.Л. Шура-Бура 3 мая 1982 года и похоронен на Новогражданском кладбище г. Рязани, участок 15.

$$
* * *
$$

1. Кирюшин В.А., Козеевская Н.А., Сметанин В.Н. Шура-Бура Борис Лукич: к 110-летию со дня рождения // Российский медико-биологический вестник имени академика И.П. Павлова. 2016. Т.24, № 4. С.173-176.

2. Шура-Бура Борис Лукич: Автобиография (1967).

3. Личный листок по учету кадров (1967) // Архив РМИ. Личное дело (1967-1974).

4. Памяти Бориса Лукича Шура-Бура: [Некролог] // Мед. паразитология и паразитарные болезни. -1983.-№1.C.88-89.

5. Шура-Бура Б.Л. // 60 лет на Рязанской земле (1950-2010): материалы по истории Рязанского гос. мед. ун-та им. акад. И.П. Павлова / авт. - сост.: Н.А. Козеевская; под ред. д.м.н., проф. Д.Р. Ракиты, д.м.н., проф. В.А. Кирюшина; РязГМУ им. акад. И.П. Павлова; науч. б-ка. - Рязань, 2010.- С.262-263.

6. Книга памяти Рязанского государственного медицинского университета имени академика И.П. Павлова/сост.: Н.А. Козеевская; под ред. д.м.н., проф. Р.Е. Калинина, д.м.н., проф. В.А.Кирюшина; ФГБОУ ВО РязГМУ Минздрава России.- Рязань: РИО РязГМУ, 2015.-С.273-274.

\title{
Собянин А.В. \\ Углеводная модификация фибриногена и фибрина в условиях гипергликемии как фактор изменения структуры и свойств тромба (обзор литературы)
}

Кубанский государственный медицинский университет Министерства здравоохранения Российской Федерации (Россия, Краснодар)

doi: 10.18411/trnio-12-2021-326

\section{Аннотация}

Сердечно-сосудистые и цереброваскулярные заболевания часто бывают сопряжены с развитием тромбоза. В процессах свертывания крови важную роль играют структура и свойства образующегося тромба. Изменения структуры тромба могут приводить к 
изменению его свойств. При некоторых фоновых заболеваниях и состояниях может происходить избыточное сиалирование (гликозилирование) и гликирование белков свертывающей системы крови, в частности, фибриногена, из которого впоследствии образуется фибрин, формирующий фибриновый каркас тромба. Такие модификации предположительно не только нарушают каскад гемокоагуляции, но и снижают восприимчивость тромба к фибринолизу. Следовательно, важно знать механизмы гликирования и гликозилирования белков свертывающей системы и их влияние на структуру и свойства тромбов для коррекции возможных нарушений гемокоагуляции и фибринолиза.

Поэтому в этом обзоре рассмотрены структура фибриногена и фибрина и биохимические механизмы их модификации углеводами, влияние этой модификации на процессы свертывания крови и фибринолиза, а также определены перспективы дальнейших исследований.

Цель: анализ научной информации о механизмах углеводной модификации фибриногена при гипергликемии для патогенетического обоснования исследований в аспекте лечения и профилактики осложнений сахарного диабета.

Ключевые слова: фибриноген, фибрин, гликозилирование, гликирование, гемокоагуляция, фибринолиз, тромбоз, гипергликемия.

\section{Abstract}

Cardiovascular and cerebrovascular diseases are often associated with the development of thrombosis. In the processes of blood coagulation, the structure and properties of the resulting thrombus play an important role. Changes in the structure of a thrombus can lead to a change in its properties. In some underlying diseases and conditions, excessive sialylation (glycosylation) and glycation of proteins of the blood coagulation system, in particular, fibrinogen, from which fibrin is subsequently formed, which forms the fibrin framework of a thrombus, may occur. Such modifications presumably not only disrupt the hemocoagulation cascade, but also reduce the susceptibility of the thrombus to fibrinolysis. Therefore, it is important to know the mechanisms of glycation and glycosylation of proteins of the coagulation system and their effect on the structure and properties of blood clots to correct possible disorders of hemocoagulation and fibrinolysis.

Therefore, this review considers the structure of fibrinogen and fibrin and the biochemical mechanisms of their modification by carbohydrates, the effect of this modification on the processes of blood coagulation and fibrinolysis, and also identifies the prospects for further research.

Keywords: fibrinogen, fibrin, post-translational modifications, glycosylation, glycation, hemocoagulation, fibrinolysis, thrombosis, hyperglycemia.

\section{Введение}

Строение и свойства тромба являются важными детерминантами болезней и смертности, связанных с сердечно-сосудистой патологией [1-7]. Одним из основных факторов, определяющих характеристики тромба, являются изменения в молекуле фибриногена, которые могут влиять на скорость гемокоагуляции, структуру фибринового матрикса и его восприимчивость к фибринолизу [1, 8-9]. Следовательно, важно знать влияние изменчивости молекулы фибриногена на каскад свертывания и характеристики сгустка [1].

Фибриноген, из которого впоследствии образуется нерастворимый фибрин, лежащий в основе каркаса тромба, подвергается посттрансляционным модификациям, в том числе модификации углеводами [1, 9]. В норме молекула фибриногена может быть модифицирована 0, 1 или 2 сиаловыми кислотами (гликозилирование) [1, 10-12]. При патологических состояниях, сопровождаемых гипергликемией (сахарный диабет), и глюкоза плазмы крови способна самопроизвольно связываться с белками, в том числе и с 
фибриногеном [1, 9-10]. Этот процесс носит название гликирование и может происходить также при нормальном уровне глюкозы в крови в условиях окислительного стресса при воспалении или возрастных заболеваниях $[1,9]$. Известно, что фибриноген гликируется по остаткам лизина [1,13]. Углеводная модификация молекул фибриногена приводит к изменению их структуры $[1,9]$. Поэтому можно предположить, что подобные модификации приводят к изменению структуры и свойств образующегося из фибриногена фибрина, a, следовательно, и тромба $[1,9,14]$. Кроме того, такой модификации предположительно может подвергнуться фибрин в уже образовавшемся тромбе. Знание влияния гликозилирования и гликирования фибринового матрикса на восприимчивость тромба к фибринолизу может быть важным для понимания механизмов лизиса тромбов в условиях гипергликемии.

\section{Строение и функции фибриногена/фибрина}

На рисунке 1 изображена структура молекулы фибриногена. Фибриноген (340 кДа) представляет собой гликопротеин, который синтезируется гепатоцитами и циркулирует в крови здоровых людей в концентрациях от 2 до 4 г / л [1]. Молекулы фибриногена состоят из двух идентичных единиц, каждая из которых состоит из трех полипептидов: А $\alpha$ (610 аминокислотных остатков, 67 кДа), В $\beta$ (461 кДа, 56 кДа) и $\gamma$ (411 аминокислотных остатков, 48 кДа) [2, 15]. Цепи удерживаются вместе 29 дисульфидными мостиками [15]. В молекуле фибриногена можно различить основные структурные области [16]. Центральная область Е содержит аминокислотные концы всех шести полипептидных цепей, которые формируют сайты связывания тромбина $[1-2,17]$. Области D - 2 дистальных узелка, содержащие карбоксильные окончания цепей В $\beta$ и $\gamma$ и связанные с областью Е двумя $\alpha$-спиральными доменами в форме спирали [17]. Карбоксильные концы цепей А $\alpha$ образуют более гибкие и подвижные $\alpha$ С-области [17].

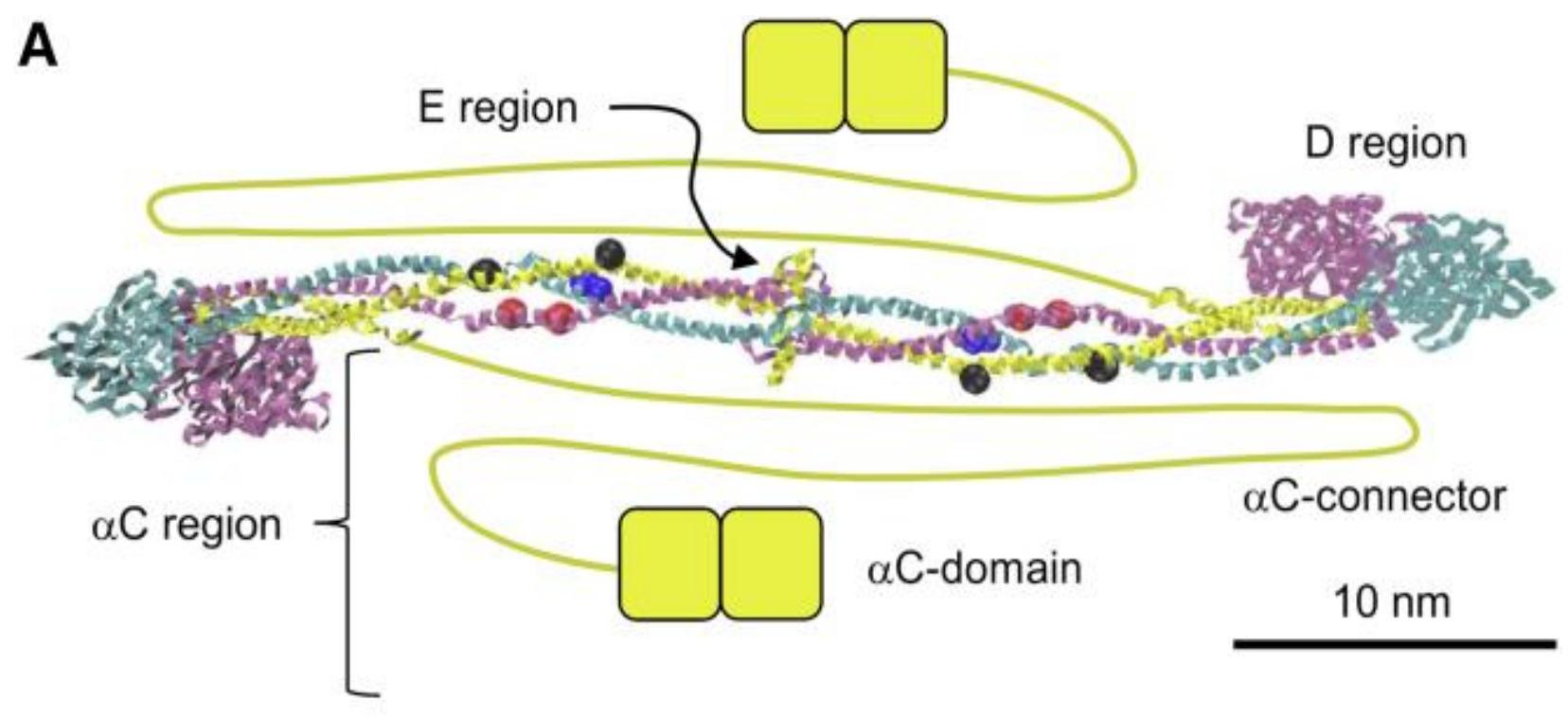

Рисунок 1. Кристаллическая структура фибриногена человека. E region- центральная область E. D regionтерлинальные области D. $\alpha C$ region - подвижные и гибкие $\alpha C$-области, содержащие карбоксильные концы ųenей $A \alpha$ [17], [18]

Заключительным этапом каскада коагуляции является расщепление тромбином связей у остатков аргинина и глицина в цепях $\mathrm{A} \alpha$ и $\mathrm{B} \beta$ в области $\mathrm{E}$, в результате чего высвобождаются фибринопептиды А и В (рис. 2, 3) [19]. Таким образом, образуются мономеры фибрина и инициациируется его полимеризация [1]. Под действием тромбина также происходит активация фактора XIII, который сшивает $\gamma$-цепи или $\alpha$-цепи с соседними молекулами фибрина путем образования ковалентных связей между остатками глутамина и лизина [20-21]. В результате повышается стабильность фибриновой сети [21]. 
B

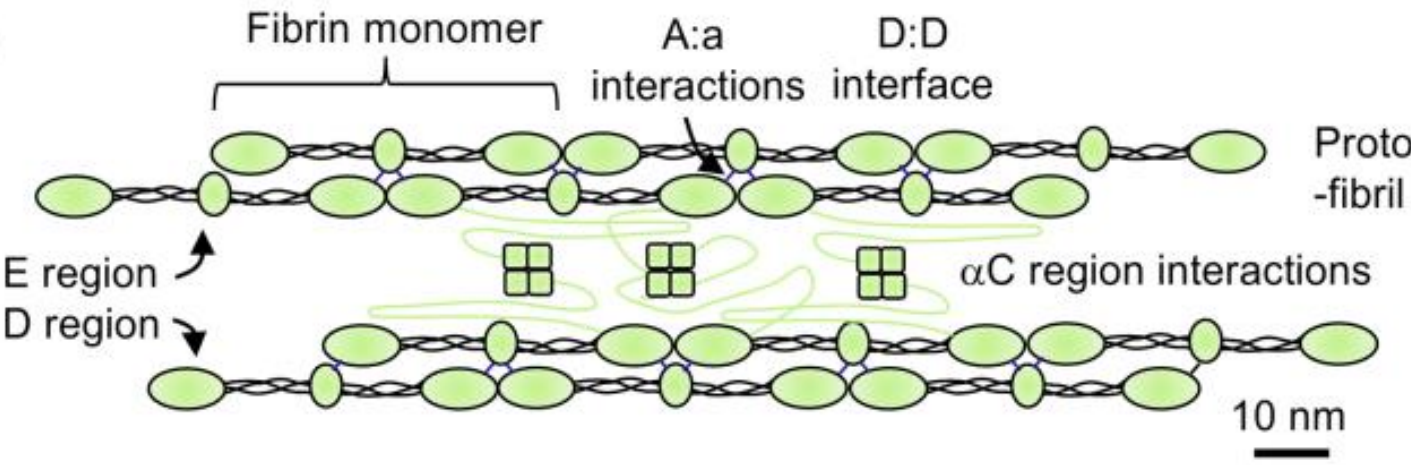

Рисунок 2. Фибриновые взаимодействия. Наполовину ступенчатая сборка мономеров фибрина в двухиепочечные протофибриллы в основном опосредуется взаимодействиями А: выступ-отверстие и взаимодействием D: D, и в меньшей степени взаимодействиями B: b-выступ-отверстие (не показано). Боковая (радиальная) сборка протофибрилл в зрелье волокна, как полагают, в основном опосредуется взаимодействиями $\alpha$ - С областей, что приводит к плотной сложной сети $\alpha$ - С областей между протофибриллами. Для ясности не все области $\alpha$ - С показаны в пространстве между протофибриллами. [18]

D

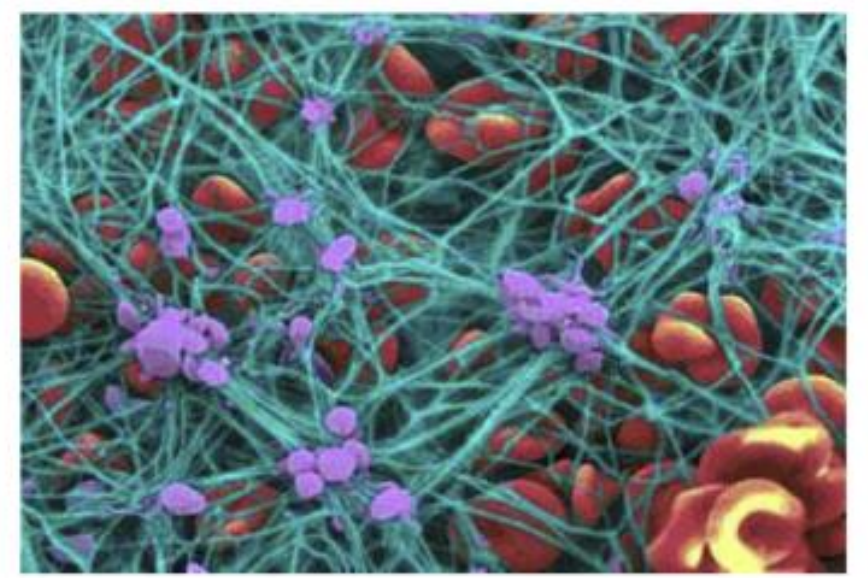

\section{$10 \mu \mathrm{m}$}

Рисунок 3. Микрофотография сгустка крови с помощзью сканирующего электронного микроскопа 8 искусственных изветах. Зеленые, фибриновые волокна; пурпурный - тромбоциты; красный - эритроцит (Ю. Веклихом и Дж. У. Вайзелем, Медицинский факультет Университета Пенсильвании). [18]

Стоит отметить, что фибриноген отличается структурной неоднородностью молекул. Гетерогенность фибриногена является результатом нескольких типов вариаций: генетический полиморфизм, альтернативный процессинг мРНК, протеолитическое расщепление, факторы окружающей среды и посттрансляционные модификации [22-24]. Посттрансляционные модификации влияют на функцию фибриногена и, вероятно, на образование сгустка, его структуру и склонность к лизису. В данном обзоре мы подробнее остановимся на гликозилировании и гликировании.

\section{Модификация белков углеводами}

Модификация белков углеводами может происходить ферментативно или самопроизвольно. Гликозилирование представляет собой ферментативный процесс, в котором сахара (гликаны или полисахариды) присоединяются к белкам АТФ-зависимым образом [2, 9]. Для нормального функционирования определенных участков белка необходимо гликозилирование. Сиалирование - это форма гликозилирования, при которой сиаловая кислота связана на конце углеводной цепи гликопротеина [10-12, 25-26].

Гликация (гликирование) - это многостадийный процесс, при котором углевод неферментативно самопроизвольно связывается с белками [1-9, 27-29]. В первую очередь, гликирование происходит по свободным аминогруппам остатков лизина с образованием глюкозиламинов (альдиминов, оснований Шиффа), которые в результате обратимой изомеризации превращаются в фруктозамины (кетоамины, соединения Амадори). Эти 
вещества называются продуктами раннего гликирования. Последующие необратимые реакции, которые включают сшивание, образование ароматических гетероциклов и окисленных соединений, протекают достаточно длительное время (месяцы, годы) и приводят к образованию конечных продуктов гликирования/продуктов завершенного гликирования (КПГ, ПЗГ). Гликирование белков возможно в присутствии глюкозы, и уровень глюкозы сильно определяет скорость гликирования $[5,9]$. Поэтому глюкоза может самопроизвольно связываться с медленно обменивающимися белками, в частности с гемоглобином, нерастворимым коллагеном сосудистой стенки, а также с белками, имеющими относительно высокую скорость обмена (белки свертывающей системы - фибриноген), однако последние в силу высокой скорости обмена в меньшей степени подвержены действию конечных продуктов гликирования. Кроме того, повышенная концентрация глюкозы в крови ассоциировано с окислительным стрессом и образованием высокореактивных продуктов, таких как метилглиоксаль, что ведет к накоплению необратимых изменений в молекулах белков $[1,9,30]$.

Гликирование происходит у пациентов с высоким уровнем глюкозы в крови, например, при неконтролируемом сахарном диабете [1, 3, 6, 9, 15, 31-33]. Нормальный уровень глюкозы составляет 3,3-5,5 ммоль / л, но у пациентов с сахарным диабетом он может повышаться до 20 ммоль / л (360 мг / дл) [1]. Также гликация может происходить при нормальном уровне глюкозы [1].Это связано с окислительным стрессом, например, наблюдаемым при воспалениях или при возрастных заболеваниях $[1,30,34]$.

\section{Гликозилирование и гликирование фибриногена/фибрина}

Каждая цепь $\mathrm{B} \beta$ и $\gamma$ фибриногена имеет 1 сайт $\mathrm{N}$-гликозилирования, который может содержать от 0 до 2 сиаловых кислот $[10,11]$. Обычно в каждой молекуле фибриногена присутствует $\approx 6$ остатков сиаловой кислоты $[12,25]$. За счет отрицательного заряда сиаловые кислоты вносят вклад в растворимость молекул фибриногена в плазме крови, предотвращая их от агрегации. Аномальное гликозилирование связано со старением и некоторыми заболеваниями; например, у пациентов с заболеванием печени наблюдается повышенный уровень содержания сиаловой кислоты в молекулах фибриногена [12].

В фибриногене гликирование in vivo и in vitro происходит по остаткам лизина [13, 32]. Процесс может происходить как при гипергликемии, так и при нормальном уровне глюкозы в крови, в условиях окислительного стресса $[1,6,9,30,35]$. Уровень гликирования в молекуле фибриногена выше при сахарном диабете 2 типа (СД2), чем у лиц, не страдающих диабетом $[6,9,35]$. Механизмы гликозилирования и гликирования аминокислот в молекулах фибриногена представлены на рисунке 4.

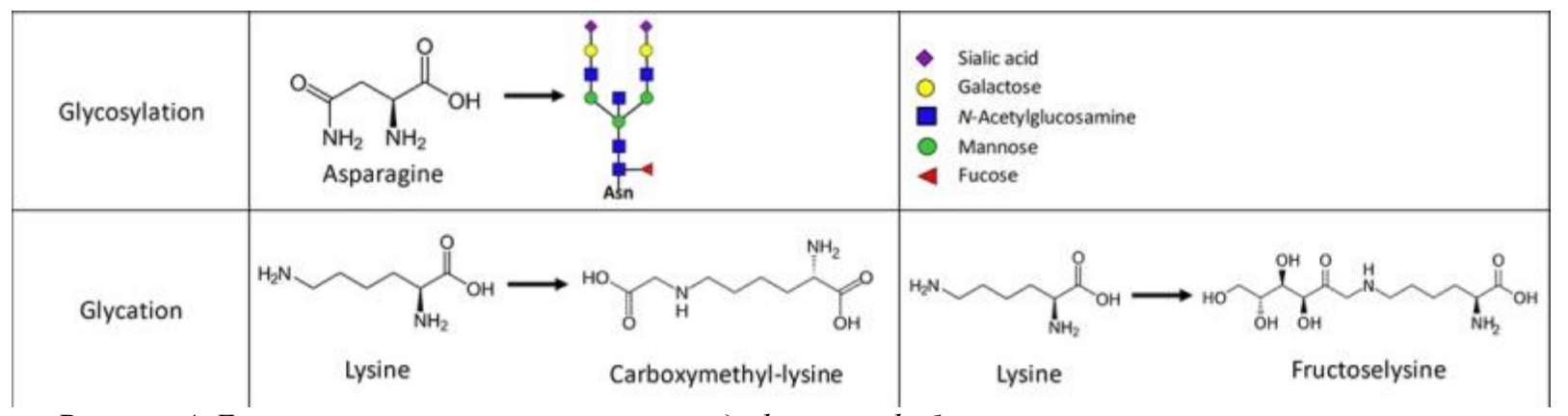

Рисунок 4. Биохимия посттранслящионных модификаций фибриногена: сверху - гликозилирование по аспарагину, снизу - гликация по лизину [1].

\section{Эффекты гликозилирования и гликирования фибриногена/фибрина в процессах свертывания крови и фибринолиза}

Скорость коагуляции зависит от количества сиаловых кислот в молекулах фибриногена. Получено, что асиалофибриноген (фибриноген, не содержащий сиаловых кислот) быстрее свертывается из-за усиления агрегации его мономера, имеет нормальную способность образовывать сшитый фибрин и существенно не отличается по своим 
метаболическим свойствам от нормального фибриногена [12, 25-26]. Фибриновый сгусток при этом более проницаемый, с большей толщиной волокон $[6,25,36]$. Следовательно, можно предположить, что усиленное сиалирование молекул фибриногена приводит к замедленному переходу фибриногена в фибрин, понижению скорости полимеризации фибрина и гемокоагуляции за счет большего отталкивания молекул фибриногена.

Кроме того, изучен эффект инкубации фибриногена разными сахарами [1]. После инкубации с различными сахарами обнаружено снижение скорости полимеризации, уменьшение максимальной мутности и диаметра волокон, а также уменьшение поперечного сшивания [37].

Показано, что гликирование фибриногена может влиять на его взаимодействие с другими белками свертывания/фибринолиза. В плазме пациентов с СД образуются фибриновые сгустки с более плотной структурой и повышенной устойчивостью к фибринолизу, чем у здоровых контрольных субъектов [33, 38-39]. В сшивании фибриновой сети с помощью FXIII, а также в связывании с фибрином различных белков, участвующих в лизисе фибрина, участвуют остатки лизина $[15,23]$. Вероятно, что связывание глюкозы в этих сайтах может иметь существенное влияние на функциональность фибриногена, что в частности проявляется измененной структурой фибриновой сети [32-33].

Исследования показывают противоречивые результаты относительно скорости полимеризации, инициирования полимеризации и максимальной мутности [1, 40-41]. Для гликирования контрольного фибриногена, или фибриногена, или плазмы крови пациентов с сахарным диабетом 1 и 2 типа в разных исследованиях использовались разные концентрации глюкозы, что может объяснить эти различия [1]. Диаметр волокон также может не меняться после гликирования [33, 42-43]. Не обнаружено различий в перекрестном связывании гликированного и контрольного фибриногена или между фибриногеном пациентов с сахарным диабетом и контрольных субъектов [1]. Исследования гликирования показывают разные результаты в отношении полимеризации, вероятно, вызванные разными условиями используемой модификации.

Немногочисленные исследования, проведенные в отношении характеристик фибриновых сгустков из гликированного фибриногена, показывают пониженную проницаемость, повышенную плотность, отсутствие заметного влияния на толщину волокон, жесткость или поперечное сшивание (на механические свойства), однако недостаточно данных о влияние гликирования на другие свойства тромба [1]. Так, Вэй Ли и соавт. обнаружили, что гликирование фибриногена не оказывает существенного систематического влияния на модуль упругости, растяжимость или время релаксации напряжения для отдельных волокон (отдельные механические характеристики отдельных фибриновых волокон тромба), однако получено, что модуль волокна $\mathrm{Y}$ сильно уменьшается с увеличением диаметра волокна D как $\mathrm{Q} \propto \mathrm{D}(-1,6)[18]$. Тонкие волокна могут быть в 100 раз жестче, чем толстые $[18,39]$. Это необычно, потому что модуль является постоянной величиной материала и не должен зависеть от размеров (диаметра) образца для однородных материалов. Это представляет интерес, поскольку известно, что тромбы с преобладанием тонких волокон в структуре фибринового матрикса труднее поддаются фибринолизу [18]. Причина преобладания тонких волокон в тромбах при гипергликемии на данный момент неизвестна, требуются дальнейшие исследования [3, 18, 39]. Также стоит отметить, что недостаточно исследованы механизмы гликирования фибрина после формирования тромба, нет данных о влиянии этого явления на характеристики тромба, на способность к фибринолизу. Ученые исходят из точки зрения, что продукты завершенного гликирования в молекуле фибриногена не успевают образовать ковалентные сшивки в силу высокой скорости обмена фибриногена, а в уже сформированном тромбе - в силу быстрой активации системы фибринолиза, разрушающей тромб [44-46]. Однако следует обратить внимание на то, что тромбы могут образовываться в условиях гипергликемии на фоне иных патологических процессов, которые дополнительно влияют на систему гемостаза (окислительный стресс, сердечно-сосудистая недостаточность). Иными словами, лица с 
гипергликемией склонны к тромбообразованию, и скорость тромболизиса может быть меньше скорости тромбоза [34, 38, 47]. Все эти факторы, действуя совместно, определяют условия для пролонгирования срока жизни образовавшегося тромба, а следовательно, и фибрина, что может обусловить формирование ПЗГ и образование ими дополнительных ковалентных связей, способных повлиять на структуру и свойства тромба. В имеющихся исследованиях указывается на снижение фибринолиза сгустка после гликирования, однако разные условия проведения экспериментов не позволяют однозначно оценить результаты $[1$, 38].

\section{Заключение}

Таким образом, определимся с основными направлениями в исследовании влияния углеводной модификации фибриногена/фибрина на строение и свойства тромба. В целом гликозилирование фибриногена приводит к снижению скорости полимеризации и более тонким волокнам в структуре фибринового матрикса тромба. Недостаточно доказательств, чтобы утверждать о влиянии гликозилирования на другие характеристики фибриновых сгустков. Гликирование молекул фибриногена не имеет преимущественного влияния на механические свойства тромба, однако зависимость других свойств при этом не доказана. Причина формирования тонких волокон в структуре фибринового матрикса остается неизвестной. Различные условия проведенных экспериментов, в частности разный уровень глюкозы в крови у пациентов, вероятно, приводят к расхождению результатов. Этот недостаток в дальнейшем необходимо устранить, в частности, путем единых требований по подбору материала и проведением однородной выборки. Имеющиеся противоречивые данные открывают перспективу для дальнейших исследований. Необходимо изучить механизмы гликирования фибрина после образования фибринового тромба, что тоже имеет значение для понимания механизмов фибринолиза в условиях гипергликемии. Также интересным представляется изучение влияния гликирования на связывание фибриногена с тромбином, фибрина с ферментами системы фибринолиза, то есть в контексте белокбелковых взаимодействий в каскаде свертывания крови.

$$
* * *
$$

1. De Vries J.J. et al. Effects of post-translational modifications of fibrinogen on clot formation, clot structure, and fibrinolysis: A systematic review // Arterioscler. Thromb. Vasc. Biol. 2019. № March. P. 554-569.

2. Bridge K.I., Philippou H., Ariëns R.A.S. Clot properties and cardiovascular disease // Thromb. Haemost. 2014. Vol. 112, № 5. P. 901-908.

3. Alzahrani S.H., Ajjan R.A. Review article: Coagulation and fibrinolysis in diabetes // Diabetes and Vascular Disease Research. 2010. Vol. 7, № 4.

4. Banga J.D. Coagulation and Fibrinolysis in Diabetes // Semin. Vasc. Med. 2002. Vol. 2, № 1.

5. Hood J.E., Yesudasan S., Averett R.D. Glucose Concentration Affects Fibrin Clot Structure and Morphology as Evidenced by Fluorescence Imaging and Molecular Simulations // Clin. Appl. Thromb. 2018. Vol. 24, № 9_suppl.

6. Kwiatkowski J. et al. The pathogenesis and available prevention options in patients with diabetic thrombophilia // Advances in Clinical and Experimental Medicine. 2018. Vol. 27, № 10.

7. King R.J., Grant P.J. Diabetes and cardiovascular disease: pathophysiology of a life-threatening epidemic // Herz. 2016. Vol. 41, № 3.

8. Schuett K. et al. Clot structure: A potent mortality risk factor in patients on hemodialysis // J. Am. Soc. Nephrol. 2017. Vol. 28, № 5.

9. Luzak B. et al. Fibrinogen glycation and presence of glucose impair fibrin polymerization — an in vitro study of isolated fibrinogen and plasma from patients with diabetes mellitus // Biomolecules. 2020. Vol. 10, № 6.

10. Clerc F. et al. Human plasma protein N-glycosylation // Glycoconj. J. 2016. Vol. 33, № 3. P. $309-343$.

11. Townsend R.R. et al. Carbohydrate structure of human fibrinogen. Use of 300-MHz H-NMR to characterize glycosidase-treated glycopeptides // J. Biol. Chem. 1982. Vol. 257, № 16. P. 9704-9710.

12. Martinez J., MacDonald K.A., Palascak J.E. The role of sialic acid in the dysfibrinogenemia associated with liver disease: Distribution of sialic acid on the constituent chains // Blood. 1983. Vol. 61, № 6.

13. Svensson J. et al. Acetylation and glycation of fibrinogen in vitro occur at specific lysine residues in a concentration dependent manner: A mass spectrometric and isotope labeling study // Biochem. Biophys. Res. Commun. 2012 . Vol. 421, № 2 .

14. Norton D.G. et al. Computational imaging analysis of glycated fibrin gels reveals aggregated and anisotropic structures // J. Biomed. Mater. Res. - Part A. 2017. Vol. 105, № 8. 
15. Litvinov R.I. et al. Fibrinogen and Fibrin // Subcell. Biochem. 2021. Vol. 96. P. 471-501.

16. Mosesson M.W. Fibrinogen and fibrin structure and functions // Journal of Thrombosis and Haemostasis. 2005. Vol. 3, № 8 .

17. Kollman J.M. et al. Crystal structure of human fibrinogen // Biochemistry. 2009. Vol. 48, № 18.

18. Li W. et al. Fibrin Fiber Stiffness Is Strongly Affected by Fiber Diameter, but Not by Fibrinogen Glycation // Biophys. J. 2016. Vol. 110, № 6.

19. Weisel J.W., Litvinov R.I. Fibrin formation, structure and properties // Subcell. Biochem. 2017. Vol. 82.

20. Wang W. Identification of respective lysine donor and glutamine acceptor sites involved in factor XIIIa-catalyzed fibrin $\alpha$ chain cross-linking // J. Biol. Chem. 2011. Vol. 286, № 52. P. 44952-44964.

21. Duval C. et al. Roles of fibrin $\alpha$ - and $\gamma$-chain specific cross-linking by FXIIIa in fibrin structure and function // Thromb. Haemost. 2014. Vol. 111, № 5.

22. De Vries P.S. et al. A meta-analysis of 120246 individuals identifies 18 new loci for fibrinogen concentration // Hum. Mol. Genet. 2016. Vol. 25, № 2.

23. Cronjé H.T. et al. Fibrinogen and clot-related phenotypes determined by fibrinogen polymorphisms: Independent and IL-6-interactive associations // PLoS One. 2017. Vol. 12, № 11.

24. De Maat M.P.M., Verschuur M. Fibrinogen heterogeneity: Inherited and noninherited // Current Opinion in Hematology. 2005. Vol. 12, № 5.

25. Martinez J., Palascak J., Peters C. Functional and metabolic properties of human asialofibrinogen // J. Lab. Clin. Med. 1977. Vol. 89, № 2.

26. Gligorijević N. et al. Structural and functional changes of fibrinogen due to aging // Int. J. Biol. Macromol. 2018. Vol. 108.

27. Perween S. et al. Post-translational modifications on glycated plasma fibrinogen: A physicochemical insight // Int. J. Biol. Macromol. 2019. Vol. 126.

28. Chandrashekar A. et al. Mechanical and Biochemical Role of Fibrin Within a Venous Thrombus // European Journal of Vascular and Endovascular Surgery. 2018. Vol. 55, № 3.

29. Krantz S. et al. Properties of in Vitro Nonenzymatically Glycated Plasma Fibrinogens // Exp. Clin. Endocrinol. Diabetes. 1987. Vol. 90.

30. Simm A. et al. Protein glycation - Between tissue aging and protection // Exp. Gerontol. 2015. Vol. 68.

31. Austin G.E., Mullins R.H., Morin L.G. Non-enzymic glycation of individual plasma proteins in normoglycemic and hyperglycemic patients. // Clin. Chem. 1987. Vol. 33, № 12.

32. Pieters M. et al. Glycation of fibrinogen in uncontrolled diabetic patients and the effects of glycaemic control on fibrinogen glycation // Thromb. Res. 2007. Vol. 120, № 3.

33. Pieters M. et al. The effect of glycaemic control on fibrin network structure of type 2 diabetic subjects // Thromb. Haemost. 2006. Vol. 96, № 5.

34. Štikarová J. et al. The effect of reagents mimicking oxidative stress on fibrinogen function // Sci. World J. 2013. Vol. 2013.

35. Li X. et al. Effects of Hyperglycemia and Diabetes Mellitus on Coagulation and Hemostasis // J. Clin. Med. 2021. Vol. 10, № 11 .

36. Maghzal G.J., Brennan S.O., George P.M. The sialic acid content of fibrinogen decreases during pregnancy and increases in response to fibrate therapy // Thromb. Res. 2005. Vol. 115, № 4.

37. Date K., Ohyama M., Ogawa H. Carbohydrate-binding activities of coagulation factors fibrinogen and fibrin // Glycoconj. J. 2015. Vol. 32, № 6.

38. Kearney K. et al. Hypofibrinolysis in diabetes: A therapeutic target for the reduction of cardiovascular risk // Cardiovascular Diabetology. 2017. Vol. 16, № 1.

39. Nair C.H. et al. Studies on fibrin network structure in human plasma. Part II - Clinical application: Diabetes and antidiabetic drugs // Thromb. Res. 1991. Vol. 64, № 4.

40. Hoffman M. Alterations of Fibrinogen Structure in Human Disease // Cardiovasc. Hematol. Agents Med. Chem. 2008. Vol. 6, № 3 .

41. Lütjens A. et al. Polymerisation and crosslinking of fibrin monomers in diabetes mellitus // Diabetologia. 1988. Vol. 31, № 11 .

42. Dunn E.J., Ariëns R.A.S., Grant P.J. The influence of type 2 diabetes on fibrin structure and function // Diabetologia. 2005. Vol. 48, № 6. P. 1198-1206.

43. Pieters M. et al. Glycaemic control improves fibrin network characteristics in type 2 diabetes - A purified fibrinogen model // Thromb. Haemost. 2008. Vol. 99, № 4.

44. Vasan S., Foiles P., Founds H. Therapeutic potential of breakers of advanced glycation end product-protein crosslinks // Archives of Biochemistry and Biophysics. 2003. Vol. 419, № 1.

45. Ансари Н.А., Рашид 3. Неферментативное Гликирование Белков: От Диабета До Рака // Биомедицинсая химия. 2010. Vol. 56, № 2.

46. Терапевтический потенциал разрывателей поперечных сшивок гликированных белков // Вестник Волгоградского государственного медицинского университета. 2016. № 1 (57).

47. Matsuda T. et al. Mechanism on disorders of coagulation and fibrinolysis in diabetes // Diabetes. 1996. Vol. 45, № 3 SUPPL. 